\title{
Governança ambiental e economia verde
}

\author{
Environmental governance and the green economy
}

Pedro Roberto Jacobi ${ }^{1}$

Paulo Antonio de Almeida Sinisgalli ${ }^{2}$

${ }^{1}$ Faculdade de Educação, Universidade de São Paulo. Av. da Universidade 308,

Cidade Universitária. 05508-900 São Paulo SP. prjacobi@usp.br

${ }^{2}$ Escola de Artes, Ciências e Humanidades,

Universidade de São Paulo (EACH-USP).

\begin{abstract}
The Rio+20 Conference will mobilize the global community in 2012 to participate in a challenging debate on the global environmental reality and the existing modus operandi with respect to the broad and generic topics of development and the environment. One of the core themes of this meeting is the transition to a green economy in the context of sustainable development and the eradication of poverty. The issue of Global Environmental Governance will top the agenda of the Rio +20 discussions, with a view to promoting and accelerating the transition to sustainable societies. It presents, often in a controversial way, the creation of conditions to define new institutional spaces and shared decisionmaking processes. Before embarking on the discussion about what king of sustainability should be behind the Green Economy, and its applicability, the scope of this article is to ask readers to reflect on what should be the priority in the discussion on environmental governance This should be explained to the extent that there is a need to change the existing mechanisms of profoundly unequal exploitation of resources, which blocks progress in decision-making processes, as decisions of the few create a perverse logic of appropriation of natural resources and the non-resolution of social exclusion.
\end{abstract}

Key words Green economy, Governance, Ecological economy, Natural resources, Rio+20
Resumo A Conferência Rio+20 mobiliza a comunidade global em 2012 para participar de um desafiador debate sobre a realidade ambiental global e modus operandi existente quanto à temática ampla e genérica do desenvolvimento e do ambiente. Um dos temas estruturantes desta reunião é a transição para uma economia verde no contexto do desenvolvimento sustentável e da erradicação da pobreza. O tema da Governança Ambiental Global um dos carros chefe do debate na Rio+20, no intuito de promover e acelerar a transição rumo a sociedades sustentáveis, configura a construção muitas vezes, de forma controversa, das condições para a definição de novos espaços institucionais e processos decisórios compartilhados. Este artigo propõe aos leitores uma reflexão para discutir que tipo de sustentabilidade está por trás da economia verde, a sua aplicabilidade e o que deva ser priorizada na discussão de governança ambiental. Isto se explica na medida em que existe a necessidade de mudar os mecanismos de utilização dos recursos, profundamente injustos, e que impedem avanços nos processos decisórios, pois as decisões de poucos tem configurado uma lógica perversa de expropriação de recursos naturais e não resolução da exclusão social.

Palavras-chave Economia verde, Governança, Economia ecológica, Recursos naturais, Rio +20 


\section{Introdução}

A Conferência Rio+20 mobiliza a comunidade global em 2012 para participar de um desafiador debate sobre a realidade ambiental global e modus operandi existente quanto à temática ampla e genérica do desenvolvimento e do ambiente. Esta Conferência ocorre num contexto marcado por um aumento das incertezas relacionadas com o presente quadro de degradação ambiental e da necessidade de buscar, através das inovações tecnológicas e de novas formas de cooperação, sob um ponto de vista de transição paulatina, mudanças que se fazem absolutamente estratégicas para a governança global.

Mas também se coloca a necessidade de avançar para além da resposta à situação preocupante quanto aos problemas ambientais contemporâneos, na busca de avançar numa meta permanentemente prometida, mas não realizada: a erradicação da pobreza e das desigualdades recorrentemente explicitadas a partir da definição das Metas do Milênio, e das questões que estão colocadas para mudanças na lógica prevalecente da economia global.

Um dos temas estruturantes desta reunião é a transição para uma economia verde no contexto do desenvolvimento sustentável e da erradicação da pobreza. O tema tem despertado muitos questionamentos e polêmicas. E a visão do Programa das Nações Unidas para o Meio Ambiente enfatiza aspectos que concebem a Economia Verde sustentada em três pilares: pouca intensidade em carbono, eficiente no uso dos recursos naturais; e socialmente inclusiva. A temática é recente e a palavra chave transição abre espaço para um debate sobre os padrões de produção e consumo e a necessidade de rever o modelo de desenvolvimento ainda prevalecente. Neste sentido, o questionamento que se faz é se os pilares da economia verde são suficientes para a efetiva erradicação da pobreza e garantia de sustentabilidade planetária?

As polêmicas tem se dado em torno de dois temas, o desafio de mudanças na vida cotidiana e sua relação com o desenvolvimento sustentável, e a preocupação com a ampliação de uma visão que enfatiza a expansão dos processos de mercantilização da natureza e privatização dos bens comuns, em particular os serviços ecossistêmicos.

Mas também existe uma corrente de pensamento $^{1}$ que destaca a centralidade e a defesa dos bens comuns da humanidade como resposta à mercantilização, privatização e financeirização da vida, implícita no conceito de economia verde, o que redundaria em mais concentração de riqueza e poder e em maior desigualdade social.

Pode-se destacar ainda outros aspectos relevantes deste debate. Sob o ponto de vista de mercantilização da natureza, a ausência de referência econômica dos recursos e serviços ecossistêmicos é um fator que contribui ainda mais sua degradação. Por outro lado, uma abordagem meramente econômica não consegue captar todo o universo de valores.

Porém, o reconhecimento dos bens comuns como fatores inerentes aos processos econômicos induz à necessidade de se repensar a distribuição desta riqueza gerada. Além disso, todos estes fatores devem ser olhados à luz do entendimento dos limites impostos pelo próprio ambiente, o que não está explicitamente incluído no debate da economia verde.

$\mathrm{O}$ artigo tem como finalidade trazer ao leitor o debate sobre a Governança Ambiental Global como um dos carros chefe do debate, na Rio+20, no intuito de promover e acelerar a transição rumo a sociedades sustentáveis, considerando aspectos econômicos, sociais e ambientais, e suas interações.

\section{Governança ambiental \\ - elementos para o debate}

As aceleradas mudanças no plano social, econômico, tecnológico e ambiental desafiam cada vez mais as estruturas tradicionais dos governos.

O uso do termo "governança" reflete o deslocamento nas áreas de ciências sociais e de políticas públicas de abordagens focadas no conceito de governo para um conceito mais abrangente de governança que incorpora os atores não estatais.

Governança é uma palavra e um conceito que tem se difundido muito, sendo hoje utilizado de forma bastante generalizada, seja no campo das ideias políticas, econômicas ou científicas. Abrange diferentes visões e significados, e suas múltiplas dimensões e usos possíveis permitem uma abordagem bastante ampla.

Nos anos 70, a palavra "governança" era entendida como "governar", e governo como processo. Atualmente, o termo "governança" é usado principalmente para indicar um novo modo de governar, que difere dos modelos hierárquicos tradicionais nos quais as autoridades de estado exercem controle soberano sobre as pessoas e grupos da sociedade civil ${ }^{2}$.

Ao falarmos de governança nos referimos basicamente a um modo não hierárquico de governo, onde atores não-estatais, e diversos seg- 
mentos participam na formulação e implementação de políticas públicas ${ }^{3}$.

O conceito de governança tem se difundido desde os anos 1980 como uma referência da modernidade da ação pública e da gestão empresarial. Os diferentes significados e aplicações nos diferentes contextos possuem combinações de usos descritivos e normativos. Alguns se referem à governança numa escala muito ampla, como a usada pelas Nações Unidas ou para a governança não governamental (governança corporativa).

Para Kooiman ${ }^{4}$ o conceito de "Governança" se baseia em multiplicidade de atores, sua interdependência, objetivos compartilhados, fronteiras fluídas entre público, privado e esferas associativas e multiplicidade de formas de ação, intervenção e controle ${ }^{5}$.

Outros tipos de governança têm sido utilizados em nível de cidades: a boa governança, que enfatiza transparência, accountability e efetividade como condições necessárias para o sucesso de uma política pública e a governança multiescalar que tem o desafio de articular as ações de atores públicos independentes visando objetivos compartilhados em diferentes níveis territoriais.

A governança ambiental envolve todos e cada um nas decisões sobre o meio ambiente, por meio das organizações civis e governamentais, a fim de obter ampla e irrestrita adesão ao projeto de manter a integridade do planeta.

$O$ conceito se centra na transformação das formas de governo e regulação que transcende as tradicionais hierarquias do estado e dos sistemas de mercado. A interpretação que prevalece, a partir desta abordagem, é que a governança representa um processo que decorre da articulação entre formas clássicas de autoridade existentes no estado (organização hierárquica) com aquelas características do setor privado (direcionado pela competição do mercado) e o setor voluntário ou sociedade civil(caracterizado pela ação voluntária, recíproca e solidária dos cidadãos $)^{6}$.

Os críticos entendem ser uma visão idealizada, pois apresenta o Estado, os mercados e a Sociedade Civil como parceiros que tem uma mesma lógica, o que desconsidera as assimetrias existentes. Também se questiona o fato de que em muitos casos, a noção pode escamotear a partir da prevalência de uma visão instrumental a noção de conflito, enfatizando a importância de parcerias para tornar eficaz a implementação de uma política.

Cabe enfatizar que ao falarmos de Governança Ambiental nos referimos a um conceito que transcende um simples conjunto de formatos de gestão. Podemos desdobrá-la em sua dimensão instrumental, sua dimensão de compartilhamento baseada na participação ampliada em todos os processos, o que demanda o envolvimento ativo de todas as partes interessadas (stakeholders) em agendas pautadas pela busca de cooperação e consenso. O maior desafio é de avançar na direção de acordos baseados em pontos comuns que possam produzir avanços nos processos de fortalecimento de políticas públicas ambientais no sentido de reduzir os problemas provocados por ações predatórias ao ambiente. $\mathrm{O}$ que se tem visto atualmente é que esta não tem sido a dinâmica atual das decisões de caráter planetário, pautado mais pelos interesses de uma minoria.

O conceito de governança refere-se ao conjunto de iniciativas, regras, instâncias e processos que permitem às pessoas, por meio de suas comunidades e organizações civis, a exercer o controle social, público e transparente, das estruturas estatais e das políticas públicas, por um lado, e da dinâmica e das instituições do mercado, por outro, visando atingir objetivos comuns. A literatura sobre o tema enfatiza a governança, como a realizada através da participação, envolvimento e negociação de multiatores (multistakeholders), da descentralização (transferindo o poder para o governo local (empowerment), da unidade de gestão ambiental, e de mecanismos para a resolução dos conflitos ${ }^{6}$.

A Governança Ambiental está relacionada com a implementação socialmente aceitável de políticas públicas, um termo mais inclusivo que governo, por abranger a relação Sociedade, Estado, mercados, direito, instituições, políticas e ações governamentais, associadas à qualidade de vida bem estar, notadamente os aspectos relacionados com a saúde ambiental. Isto implica no estabelecimento de um sistema de regras, normas e condutas que reflitam os valores e visões de mundo daqueles indivíduos sujeitos a esse marco normativo. A construção desse sistema é um processo participativo, e acima de tudo, de aprendizagem. O fato é que a governança no nível territorial tem sido associada e articulada através de parcerias, coalizões, alianças entre diferentes atores em iniciativas coletivas; promovendo interações do governo com outros atores - setor privado e não governamental e entre atores governamentais na medida em que segundo Kooi$\operatorname{man}^{4}$ nenhum ator, público ou privado, dispõe nem do conhecimento nem da informação para resolver problemas complexos, dinâmicos e diversificados; e isto demanda interdependências, que mos- 
tram as limitações do governo e a necessidade de fortes laços com os governos locais, o setor privado $e$ as organizações sociais.

Como Richard e Rieu ${ }^{7}$ afirmam, no lugar de ser sustentada seja pelo estado ou pelo mercado, a governança sociopolítica gera novas formas de interação que baseadas numa visão da complementaridade entre o governo e a sociedade e pode promover compartilhamento de responsabilidade e accountability entre atores públicos, privados e o ambiente.

Isto demanda fortalecimento da cooperação e inovação na negociação de conflitos entre múltiplos atores, enfatizando práticas participativas e coordenação entre políticas públicas e atores da sociedade civil ${ }^{5,8,9}$.

Observa-se que a participação enquanto componente da ampliação da esfera pública tem colocado uma demanda à sociedade quanto a obter uma maior influência sobre o Estado, tanto como sua limitação, assumindo que a autonomia social supõe transcender as assimetrias na representação social, assim como modificar estas em favor de uma maior auto-organização social.

A constituição destas esferas públicas simultaneamente com a ampliação do espectro de problemas tratados publicamente, destacando o ambiental, está associada ao desenvolvimento de diversas formas de participação, não apenas no sentido de Estado que permeou a sociedade, mas também no sentido de Estado permeado pela sociedade.

As transformações politico-institucionais e a ampliação de canais de representatividade dos setores organizados para atuarem junto aos órgãos públicos enquanto conquista dos movimentos organizados da sociedade civil. Isto mostra a potencialidade de constituição de sujeitos sociais identificados por objetivos comuns para transformar a gestão da coisa pública, configurando a construção de uma nova institucionalidade.

Essa perspectiva abre a possibilidade de buscar a articulação entre a implantação de práticas descentralizadoras e uma engenharia institucional que concilia participação com heterogeneidade, gerando formas mais ativas de representatividade.

Ao enfatizar o conceito de Governança Ambiental se abre um estimulante espaço para repensar as formas inovadoras de gestão, na medida em que fazem parte do sistema de governança: o elemento político, que consiste em balancear os vários interesses e realidades políticas; o fator credibilidade, instrumentos que apoiem as políticas, que faça com que as pessoas acreditem nelas e a dimensão ambiental. A Governança Ambiental não pode ser entendida, apenas, como uma construção ideológica, mas como exercício deliberado e contínuo de desenvolvimento de práticas cujo foco analítico está na noção de poder social que media as relações entre Estado, Sociedade Civil, os mercados e o meio ambiente.

Aqui se adota uma visão que identifica todos os esforços relacionados com a construção cultural para articular teorias, agendas, sujeitos e potencialidades, construção de alianças e cooperação, além de acumular energia para romper com as abordagens verticais e estanques das atividades humanas e transcender aquelas que se baseiam na supremacia do mercado.

Esta noção transcende, portanto, uma abordagem de caráter técnico-institucional e se insere no plano das relações de poder e do fortalecimento de práticas de controle social e constituição de públicos participativos ${ }^{6,10}$.

Situações de conflito e de assimetrias de poder são frequentes nos mecanismos mais relevantes para assuntos ambientais no Brasil: os conselhos de meio ambiente em níveis federal, estadual e municipal, os relatórios de impacto ambiental as audiências públicas e os comitês de bacias hidrográficas. Nessas situações, ressaltase o significado que as assimetrias de poder e informação têm no processo ${ }^{11}$.

Pode-se, portanto entender governança como um processo que envolve tomadores de decisão e não tomadores de decisão, com objetivo comum: o problema a ser enfrentado e o desenho da gestão ambiental, onde a participação descentralizada e corresponsável seja a tônica do processo. Pressupõe atuação em rede, atuação integrada e o ganho de poder dos atores envolvidos na gestão, interagindo com os tomadores de decisões.

O fortalecimento da governança ambiental pode ter muitas estratégias (institucionais ou não), como as arenas de negociação, as práticas educativas e a participação da sociedade civil, ferramentas para contribuir para o processo de construção de tomada de decisão compartilhada.

Nas questões ambientais, os mecanismos para a democracia deliberativa, entendida como modelo ou ideal de justificação do exercício do poder político pautado no debate público entre cidadãos livres e em condições iguais de participação, tem avançado. Entretanto, pouco se incorporaram os grupos sociais normalmente excluídos dos mecanismos tradicionais de deliberação como atores que têm presença nos processos decisórios, o que tem se refletido na emer- 
gência de múltiplos conflitos socioambientais nos últimos anos, notadamente relacionados com a construção de usinas hidroelétricas e de obras infraestruturais que afetam a vida de cidadãos.

As relações entre Estado e Sociedade Civil podem efetivar alianças e cooperação, entretanto muitas iniciativas são permeadas por conflitos que decorrem das assimetrias sociais e das desiguais formas de organização e participação dos diversos atores envolvidos. Observa-se que nos processos de descentralização e cogerenciamento dos recursos naturais; nos arranjos onde atores interagem de forma cooperativa representando diversos segmentos - poder público, sociedade civil organizada e iniciativa privada - existe alguma forma de sinergia entre o poder público e a sociedade, que estabelece um capital social que tem importância nas relações entre os diversos segmentos, melhorando o entendimento das necessidades de se manter a qualidade ambiental.

Os impactos das práticas participativas na gestão, apesar de controversas, apontam para uma nova qualidade de cidadania, que abre novos espaços de participação sociopolítica e influenciar qualitativamente na transformação do estado atual da governança ambiental no Brasil ${ }^{12}$.

O conceito de governança ambiental configura a construção muitas vezes, de forma controversa, das condições para a definição de novos espaços institucionais, para as relações entre peritos e leigos, técnicos e usuários, e entre os setores público e privado. As instâncias participativas consultivas e/ou deliberativas das políticas ambientais podem ser consideradas instâncias abertas a essas conexões educativas, a exemplo dos conselhos de meio ambiente, dos comitês de gestão de bacias hidrográficas e das audiências públicas, que podem cumprir o papel de serviço à democracia e à proteção ambiental ${ }^{12}$.

Mas também os encontros e eventos de articulação intelectual e política em que se dê visibilidade e continuidade às discussões sobre a gestão ambiental participativa. Essas formas educativas de engajamento na transversalidade dos grupos, dos interesses, dos movimentos sociais, culturais, na vida, são tessituras que flexibilizam e potencializam politicamente as estruturas rígidas de formação do sujeito e de seus grupos de pertencimento.

As diferentes engenharias institucionais sobre as transformações em curso nos organismos colegiados mostram que a implantação efetiva dos diversos instrumentos de participação pode mudar os padrões de governança, estabelecendo novas mediações entre Estado e sociedade civil, ba- seadas no aprimoramento de suas relações democráticas e na melhoria das condições de vida, enfatizando os aspectos que afetam diretamente a saúde dos indivíduos, notadamente os mais pobres.

Poderão representar uma possibilidade efetiva de transformação da lógica de gestão da administração pública nos estados e municípios, abrindo um espaço de interlocução muito mais complexo e ampliando o grau de responsabilidade de segmentos que sempre tiveram participação assimétrica na gestão pública.

O trabalho intersetorial se apresenta como uma importante contribuição, estabelecendo melhores condições para uma lógica cooperativa, abrindo possíveis espaços não só para a sociedade civil, mas também para os sistemas peritos na gestão ambiental.

Entende-se que um novo modelo de governança ambiental deveria passar pelo redesenho das instituições governamentais de meio ambiente e, simultaneamente, incluir nas políticas setoriais a sustentabilidade socioambiental.

\section{Economia Verde \\ - um conceito e seus contraditórios}

Um dos temas estruturantes desta reunião é a transição para uma economia verde no contexto do desenvolvimento sustentável e da erradicação da pobreza. O tema tem despertado muitos questionamentos e polêmicas e a visão do Programa das Nações Unidas para o Meio Ambiente enfatiza aspectos que concebem a Economia Verde sustentada em três pilares: pouca intensidade em carbono, a eficiência no uso dos recursos naturais e a ênfase na inclusão social. A temática é recente e a palavra chave transição abre espaço para um debate sobre os padrões de produção e consumo e a necessidade de rever o modelo de desenvolvimento ainda prevalecente, e seus impactos diretos na saúde. A relação entre saúde e economia verde pode ser associada com os efeitos provocados pelas alterações climáticas nos diversos setores- habitação, transporte, fontes de energia e saneamento básico sobre a saúde, e notadamente dos setores mais excluídos da sociedade.

Os movimentos sociais veem na definição uma nova roupagem para o sistema econômico, que até implicaria melhorias em áreas como eficiência energética e gerenciamento dos recursos naturais, através de sua monetização, mas que não modificaria a lógica econômica prevalecente em seus fundamentos, sobretudo no tangente à maximização do lucro, ao rebaixamento dos cus- 
tos de produção e - principalmente - à mercantilização da vida e da natureza. Estes entendem que Economia Verde seria a ponta de lança de um novo ciclo do capitalismo, ou um eco-capitalismo, na medida em que transformaria bens comuns (como a água, a atmosfera, as florestas, oceanos e mesmo os seres vivos) em mercadorias propícias à apropriação privada, à acumulação e à especulação.

Numa perspectiva menos radical, mas ainda estrutural, questiona-se que a Economia Verde, conduzida pela lógica de mercado, tenderia a abrigar predominantemente medidas superficiais, de pouca relevância, porém mais atrativas no curto prazo, gerando apenas uma ilusão de avanço rumo à sustentabilidade. Além disso, mantém alguns pressupostos questionáveis que através da precificação dos recursos e dos serviços ecossistêmicos estes seriam utilizados de forma mais eficiente, garantindo a sua sustentabilidade. Entretanto, esta abordagem está ancorada na ideia de que os recursos naturais são ou inesgotáveis ou substituíveis, fato que não se sustenta.

Por essas mesmas razões, tender-se-ia a manter a concentração de capital, e a favorecer os mais ricos e a impedir que soluções realmente transformadoras emergissem, mantendo as causas estruturais das desigualdades sociais e econômicas.

A visão da economia ecológica questiona os pressupostos da Economia Verde sob o prisma do descolamento, na medida em que não se pode manter a perspectiva de crescimento econômico constante, mesmo com ganhos em eficiência energética e no uso de matérias-primas, em um planeta finito.

As polêmicas tem se dado em torno de dois temas, o desafio de mudanças na vida cotidiana e sua relação com o desenvolvimento sustentável, e a preocupação com a expansão de uma visão que enfatiza a expansão dos processos de mercantilização da natureza e privatização dos bens comuns, em particular os serviços ecossistêmicos.

Uma corrente de pensamento ${ }^{1}$ que destaca a centralidade e a defesa dos bens comuns da humanidade como resposta à mercantilização, à privatização e à financeirização da vida, implícita no conceito de economia verde, vê que esta última promoveria mais concentração de riqueza e poder e em maior desigualdade social.

Pode-se destacar ainda outros aspectos relevantes deste debate. Sob o ponto de vista de mercantilização da natureza, a ausência de referência econômica dos recursos e serviços ecossistêmicos é um fator que contribui ainda mais sua degradação. Porém, o reconhecimento dos bens comuns como fatores inerentes aos processos econômicos induz à necessidade de se repensar a distribuição desta riqueza gerada. Porém, todos estes fatores devem ser olhados à luz do entendimento dos limites impostos pelo próprio ambiente, o que não está explicitamente incluído no debate da economia verde.

Concomitantemente, a este aspecto também se questiona a pouca atenção dada à necessidade de controle social sobre os poderes econômicos; e à necessidade de agir sobre a desigualdade e os padrões de produção e consumo não sustentáveis.

Pela primeira vez na história do Planeta o próprio equilíbrio do sistema climático é modificado por razões fundamentalmente antrópicas, a partir da emissão de gases de efeito estufa intensificada desde a Revolução Industrial e, sobretudo, desde a segunda metade do Século XX com a explosão no uso de combustíveis fósseis como base do crescimento mundial.

Ignacy Sachs tem enfatizado que estamos na "Era do Antropoceno", expressão que foi popularizada pelo geoquímico holandês Paul Crutzen, Prêmio Nobel de Química em 2002, para determinar as mudanças no planeta ocasionadas pelo homem a partir do início da Revolução Industrial. Dentre os principais elementos por trás do risco, destaca-se uma população mundial que deve subir dos atuais 7 bilhões para 9 bilhões em meados do século, mas também o consumo ineficiente e danoso de recursos, e segundo Will Steffen, chefe do Instituto de Mudanças Climáticas da Universidade Nacional Australiana, disse que o Antropoceno estava empurrando alguns ecossistemas da Terra para "pontos sem retorno"13.

O que um número cada vez maior de cientistas afirma é que no prazo de poucas décadas, muitos ecossistemas vitais poderiam sofrer danos duradouros ou irreversíveis por causa do aquecimento provocado pelo homem. Para Santos $^{1}$, a perspectiva de propor alternativas representa a passagem gradual de uma civilização antropocêntrica para uma civilização biocêntrica, redefinir a forma de viver com qualidade de vida, promover energias que não impliquem expulsões de camponeses e indígenas dos seus territórios e desenhar políticas de transição para os países cujos orçamentos dependam excessivamente da extração de matérias primas.

A proposta de uma Economia Verde que procure direcionar o crescimento econômico para investimento do setor público e privado na redução das emissões de carbono e poluição, enquanto utiliza de recursos de forma mais eficiente, além de prevenir as perdas da biodiversidade 
e serviços ecossistêmicos ${ }^{14}$, mostra claramente que alguns pontos de consenso devem ser atacados prioritariamente:

1) O reconhecimento da contribuição do capital natural na promoção da riqueza, no sentido de prevenir perdas da biodiversidade e dos serviços ecossistêmicos;

2) A necessidade de se combater a ameaça representada pelas mudanças climáticas, através a redução das emissões de carbono e poluição; e,

3) A redução do desperdício no uso dos recursos naturais, tanto no sentido de diminuição da pressão sobre o ambiente, como na redução dos resíduos gerados;

De acordo com a publicação do Programa das Nações Unidas para o Meio Ambiente (PNU$\mathrm{MA}$ ), os pressupostos chaves desta nova abordagem são ${ }^{14}$ :

1) O esverdeamento da economia não apenas proporciona crescimento de riqueza, mas particularmente melhora o capital natural;

2) Relação intrínseca entre erradicação da pobreza e melhora da manutenção e conservação dos bens ecológicos

3) Novos empregos são criados, que superarão as perdas com empregos marrons.

4) O papel do capital natural e especialmente o capital natural vivo (biodiversidade e ecossistemas) não poderá ser ultrapassado no contexto destes pressupostos.

Tomando como base estes pressupostos chave, observamos que existe um papel destacado na questão do capital natural tanto no sentido de reconhecimento da sua importância para a geração de riqueza quanto no estabelecimento do seu uso, bem como de sua manutenção.

Para melhor entender esta questão e situar melhor a discussão de economia verde, traremos para este contexto uma descrição da dicotomia entre os sentidos econômico e ecológico do capital natural.

O conceito de desenvolvimento sustentável, que dá subsídio à Economia Verde, foi descrito como desenvolvimento que atende as necessidades do presente sem comprometer a capacidade de futuras gerações de atender suas próprias necessidades $^{15}$, mesmo sendo vago e impreciso, favoreceu a incorporação da questão ambiental ao discurso oficial.

Costanza ${ }^{16}$ observou que, nas diversas definições de desenvolvimento sustentável, três elementos estão sempre presentes: (a) a questão de escala sustentável da atividade econômica em relação aos mecanismos de suporte da vida; (a) a distribuição equitativa de recursos e oportuni- dades entre as gerações presentes e futuras; (c) e por fim, a alocação eficiente de recursos com adequada quantificação do capital natural. Se observarmos os pressupostos chaves da Economia Verde, este vão ao encontro das definições de desenvolvimento sustentável.

De acordo com Daly e Towsend ${ }^{17}$, escala representa o volume físico de fluxo de energia e matéria do meio ambiente, como fonte de recursos de baixa entropia, e a capacidade de receber os resíduos com alta entropia. Em outras palavras, representa a capacidade dos ecossistemas naturais em fornecer recurso para a economia e absorver os resíduos de forma a não alterar significativamente a sua condição inicial. Por seu turno, distribuição equitativa representa a divisão justa de fluxo de recursos, na forma de bens e serviços, para toda a população, atual e futura.

A ideia central da Economia Verde é que, o conjunto de processos produtivos da sociedade e as transações deles decorrentes contribua cada vez mais para o desenvolvimento sustentável, tanto em seus aspectos sociais quanto ambientais. Para isso, propõe como essencial que, além das tecnologias produtivas e sociais, sejam criados meios pelos quais fatores essenciais ligados à sustentabilidade socioambiental, hoje ignorada nas análises e decisões econômicas, passem a ser considerados.

Sob o ponto de vista econômico, para Pearce e Turner ${ }^{18}$, a manutenção de uma economia sustentável depende de dois fatores: (a) do progresso tecnológico para o melhor uso dos recursos naturais (maior eficiência); e (b) na substituição do capital produzido pelo capital natural, sendo o primeiro mais produtivo, ou seja, não está inserida a questão da escala dos recursos naturais na definição econômica. Estes dois pressupostos condicionam as duas principais correntes do pensamento econômico sobre a questão ambiental: Sustentabilidades Fraca e Forte.

Em termos econômicos, o conceito de desenvolvimento está vinculado à manutenção sustentável ou ao não declínio da capacidade de prover renda (utilidade) per capita infinitamente. Em outras palavras, significa a manutenção do capital necessário para garantir a utilidade para o futuro, o que implicaria também, de certa forma, em que o ambiente tivesse condições de prover os recursos necessários a esta condição ${ }^{19}$.

Esta abordagem econômica do ambiente mostra, teoricamente, que há a possibilidade de substitutibilidade entre capital produzido e recursos naturais, sendo que somente depende da elasticidade entre eles. Além disso, indica que o 
sistema natural (os recursos e serviços ecossistêmicos) é uma restrição relativa à expansão indefinida do sistema econômico ${ }^{20,21}$.

Para a economia verde, na medida em que se observa a necessidade de melhoria da distribuição de riqueza, e que esta mudança seja feita por uma modificação gradual da atual economia, pode-se observar que existem alguns pressupostos intrínsecos a esta abordagem: a substituição entre os recursos, a melhoria na eficiência tecnológica e a valoração do capital natural.

Assim, a substitutibilidade entre o capital natural e o capital produzido e a crença no desenvolvimento tecnológico para resolver os problemas decorrentes de escassez do recurso natural são os elementos presentes no debate entre as duas correntes: sustentabilidade fraca e forte.

A sustentabilidade fraca entende que os recursos naturais - ou na denominação mais pertinente à questão, o capital natural - são passíveis de substituição e, na medida em que há progresso tecnológico, há ampliação das possibilidades da reposição deste capital pelo produzido. $\mathrm{Na}$ visão da sustentabilidade forte é importante manter o estoque de capital natural constante, pois não é possível sua completa substituição pelo capital produzido (man-made capital).

Neste sentido, a correta contabilização do capital natural e sua valoração monetária, de acordo com Pearce et al..$^{22}$, é uma ferramenta imprescindível para o entendimento da sustentabilidade. Segundo Costanza ${ }^{23}$, somente é possível avaliar a sustentabilidade de um sistema se houver a integração do capital natural na contabilização do sistema econômico. Entretanto, o valor monetário de um recurso natural, que não necessariamente está inserido no mercado, nem sempre consegue captar todos os seus aspectos ambientais.

O conceito de capital natural foi introduzido na discussão sobre sustentabilidade no início da década de noventa. Partindo da ideia de que capital, na economia neoclássica, representa o estoque de bens que possui a propriedade de produzir outros bens e serviços no futuro, capital natural representa os recursos renováveis, os não renováveis, os serviços ecossistêmicos e as amenidades que o ambiente fornece para o bem-estar humano.

Teoricamente, o capital natural representa todos os recursos e serviços naturais utilizados pelo homem; como as águas, o petróleo, os diversos minerais, o solo, a madeira, os peixes, entre tantos outros, bem como os processos e funções do ecossistema na composição e manutenção da atmosfera e da biosfera, tais como a reci- clagem de nutrientes, formação de solo, assimilação de despejos, biodiversidade, além das amenidades estéticas, como a paisagem ${ }^{24}$.

A definição de capital natural como ativo artificial para compor a função de produção econômica de fundamento neoclássico serviu para incorporar a questão ambiental na análise econômica. Porém o valor monetário, como proposto pela Economia Verde, a ser dado a este capital não consegue abranger toda a gama de componentes da ecosfera, bem como as suas relações, que garantem a homeostase do planeta.

O meio ambiente possui propriedades, características e dinâmicas próprias, que se interrelacionam, ou seja, é um sistema organizado, que garante a manutenção da vida, e muitas destas características não são captadas pelos preços de mercado ${ }^{25,26}$.

Outro ponto relevante quanto ao uso do termo capital natural é que ele mantém a mesma lógica do crescimento da economia neoclássica que resultou nos problemas ambientais que hoje enfrentamos. Dentro da economia neoclássica, a sustentabilidade pode ser alcançada, entretanto é necessária uma mudança na estrutura institucional, como observado na economia, contudo o conceito de capital natural não aponta neste sentido $^{27}$.

A formação do valor monetário do capital natural, segundo Amazonas ${ }^{28}$, possui uma relação direta e dependente da abordagem adotada. Por um lado, na visão neoclássica, este é definido ex-ante pelas preferências individuais, que conduzem à sua internalização na análise custo-benefício, visando, em última instância, escalas sustentáveis de uso do recurso. Por outro, temos, na visão institucional ecológica, a determinação de valores com base nas características ecológicas e/ ou de fluxo de energia do recurso, que define a sua escala, para constituírem um valor monetário ex-post, dado pela atividade econômica decorrente do emprego deste recurso.

Assim, teoricamente, o valor de um bem natural possui, em última instância, dois pontos de ancoragem: socialmente julgado e o fisicamente determinado. Caso sejam integradas estas duas abordagens, talvez seja possível utilizar o conceito de capital natural de uma forma adequada para a transformação real de uma Economia Verde.

Portanto o novo arranjo conceitual, a Economia Verde, expressão que para muitos não dá conta dos desafios existentes, e que independentemente da sua denominação, indica que a transição para outra economia, considerando tem 
havido um incremento qualitativo da eco-eficiência, decorrente da queda do uso de recursos físicos (materiais de construção, biomassa, minérios e combustíveis fósseis) deve ser baseada no que deva ser realmente necessário produzir, de forma a não ser destrutivo para o planeta e de estratégias mais sustentáveis de governança

\section{Considerações Finais}

Os desastres naturais e climáticos, os problemas ligados à segurança alimentar e dos recursos hídricos, e a perda da biodiversidade são fatores que têm se agravado e que demandam resposta apropriada. Avanços na governança ambiental precisam ser cada vez mais incorporados nos processos que envolvem os tomadores de decisão e os não tomadores de decisão com um objetivo comum: maior consenso possível quanto à forma de enfrentar os problemas ambientais que se multiplicam, e o desenho da gestão para a sustentabilidade, onde a participação descentralizada e corresponsável sejam a tônica do processo. Pressupõe atuação em rede, atuação integrada; o ganho de poder dos atores envolvidos na gestão, interagindo com os tomadores de decisões.

Neste sentido, visando a melhor incorporação do conceito de economia verde integrada, deve-se partir da governança participativa para que o capital natural seja devidamente avaliado e julgado, tomando como um pressuposto básico os limites de uso e a capacidade de regeneração do meio. Estas são notadamente as críticas feitas aos documentos do PNUMA quanto à falta de questionamentos maiores sobre os atuais padrões perdulários de consumo e estilos de vida nas economias de mercado, o que indica que a economia mundial tenderá a continuar dependente das energias fósseis por muito tempo. Portanto ao se colocar a economia verde no centro do debate se cria a possibilidade de que os mais importantes tomadores de decisão econômica ocupem o cerne da questão, e sejam assim estimulados a promover mudanças na forma de uso dos recursos sobre os quais detêm o controle produtivo e distributivo.

Talvez um dos maiores desafios que se coloque em termos de governança esteja associado com a ausência de mecanismos de controle social sobre os agentes econômicos. E isto demanda encontrar meios para que o poder público (local, nacional e global) possa direcionar a força da economia conforme decisões democraticamente tomadas pela sociedade dentro de uma perspectiva que incorpore os limites impostos por um planeta finito.

Trata-se de garantir que instrumentos, inclusive acordos internacionais, possam ser efetivamente conhecidos e ter a sua implementação efetivada, seja pelos governos locais e nacionais, pelas instituições da ONU e organizações financeiras multilaterais, como pelo setor privado. Para tanto existe o desafio que haja um amplo compartilhamento pela sociedade em geral da necessidade de conhecer e mobilizar-se para reduzir os impactos das mudanças climáticas que tanto afetam as condições de vida, a qualidade ambiental, mas também de incrementar ações que atuem na redução das desigualdades e na melhoria das condições de saúde ambiental enfatizando práticas pautadas pelos princípios e diretrizes de sociedades sustentáveis. Isto demanda criar e aprimorar condições de governança, local a global, nas quais os limites biofísicos e todos seus desdobramentos sejam incorporados na discussão de um novo modelo focado na redução das desigualdades socioeconômicas. Portanto é inquestionável a necessidade de também estabelecer limites nos padrões de consumo nos países ricos com base em modelos mais sustentáveis de governança, visando garantir as condições socioambientais mais adequadas possíveis para as gerações futuras.

\section{Colaboradores}

PR Jacobi e PAA Sinisgalli participaram igualmente de todas as etapas de elaboração do artigo. 


\section{Referências}

1. Martins A. FST: Boaventura vê capitalismo e suas sete ameaças. Outras Palavras. [texto na Internet]. [acessado 2012 maio 15]. Disponível em: http://www. outraspalavras.net/2012/01/28/fst-boaventura-santosve-capitalismo-e-suas-sete-amecas/

2. Mayntz R. El Estado y la sociedad civil en la gobernanza moderna. Rev del CLAD Reforma y Democracia 2001; 21:7-22.

3. Rhodes R. Understanding Governance: Policy Networks, Governance, Reflexivity and Accountability. Buckingham: Open University Press; 1997.

4. Kooiman J. Modern Governance. New GovernmentSociety Interactions. London: Sage; 1993.

5. Grandgirard A. Towards a new leader of water policy in France? - European Water 2007; 19/20:25-35

6. Castro JE. Water Governance in the 21st Century". Rev Ambiente e Sociedade 2007; 10(2):97-118.

7. Richard S, Rieu T. Une approche historique de la gouvernance pour éclairer la gestion concertée de l'eau en France. Montpellier: AgroParis Tech; 2008.

8. Rogers P, Hall AW. Effective Water Governance. Suécia: Global Water Partnership (GWP), TEC background papers; 2003.

9. Grandgirard, A. 2007. Towards a new leader of water policy in France? - European Water 2007; 19/20:2535.

10. Warner J. Multi-Stakeholder Platforms for Integrated Water Management. Aldershot: Ashgate Publishing Limited; 2007.

11. Jacobi PR. Governança da água no Brasil. In: Ribeiro W, organizador. Governança da Água no Brasil: uma visão interdisciplinar. São Paulo: Annablume Editora; 2009. p.35-59.

12. Jacobi PR. Gestão Participativa de Bacias Hidrográficas no Brasil e os desafios do fortalecimento de espaços públicos colegiados. In: Nobre M, Schat$\tan$ Coelho V, organizadores. Participação e deliberação. São Paulo: Ed. 34; 2004. p. 270-289.

13. UOL notícias. Cientistas: sombras do 'Antropoceno' podem ofuscar a Rio+20. [acessado 2012 mar 3]. Disponível em: http://noticias.terra.com.br/ciencia/ rio20/noticias/0,,OI5686775-EI19851,00-Cientistas + sombras+do+Antropoceno+podem + ofuscar + a + Rio.html

14. United Nations Environment Programme (UNEP). Towards a Green Economy: Pathways to Sustainable Development and Poverty Eradication - A Synthesis for Policy Makers.2011. [acessado 2012 maio 15]. Disponível em: http://www.unep.org/greeneconomy/Portals/88/documents/ger/GER_synthesis _en.pdf
15. Fundação Getúlio Vargas (FGV). Nosso futuro comum. Rio de Janeiro: Editora FGV; 1987.

16. Costanza R. Economic Growth, Carrying Capacity, and the Environment. Ecological Economics 1995; 15:89-90.

17. Daly HE, Townsend TH, organizadores. Valuing the Earth: Economics, Ecology, Ethics. Cambrigde: The MIT Press; 1993.

18. Pearce D, Turner RK. Economics of Natural Resources and the Environment. New York: Harvester Wheatsheaf; 1990.

19. Neumayer E. Weak versus Strong Sustainability: Exploring the Limits of Two Opposing Paradigms. Cheltenham: Edward Elgar; 1999.

20. Romeiro AR. Economia ou Economia Política da Sustentabilidade. In: May P, Lustosa A, Vinha V, organizadores. Economia do Meio Ambiente: Teoria e Prática. Rio de Janeiro: Elsevier; 2003. p. 1-29.

21. Thirlwall AP. Growth and Development. London: MacMillan Press; 1999.

22. Pearce D, Markandya A, Barbier E. Blueprint for a Green Economy. London: Earthscan; 1994.

23. Costanza R. Economia Ecológica: uma agenda de pesquisa. In: May P, Seroa da Motta R, organizadores. Valorando a Natureza - Análise Econômica para o Desenvolvimento Sustentável. Rio de Janeiro: Editora Campus; 1994. p. 111-144.

24. Hinterberger F, Luks F, Schmidt-Bleek F. Material Flows vs. "Natural Capital". What Makes an Economy Sustainable? Ecological Economics 1997; 23(1): $1-14$.

25. Wackernagel M, Rees WE. Perceptual and Structural Barriers to Investing in Natural Capital: Economics from and Ecological Footprint Perspective. Ecological Economics 1997; 20:3-24.

26. Lima GT. Naturalizando o Capital, Capitalizando a Natureza: o Conceito de Capital Natural no Desenvolvimento Sustentável. Campinas: IE, Unicamp; 1999.

27. Stern DI. The Capital Theory Approach to Sustainability: A Critical Appraisal. Journal of Economic Issues 1997; 31(1):145-173.

28. Amazonas MC. Valor e Meio Ambiente. Elementos para uma Abordagem Evolucionista [tese]. Campinas: Unicamp; 2001

Artigo apresentado em 10/04/2012

Aprovado em 25/04/2012

Versão final apresentada em 04/05/2012 